\title{
PET Imaging of Chemokine Receptors in Vascular Injury-Accelerated Atherosclerosis
}

\author{
Yongjian Liu ${ }^{1}$, Richard Pierce ${ }^{2}$, Hannah P. Luehmann ${ }^{1}$, Terry L. Sharp ${ }^{1}$, and Michael J. Welch ${ }^{\dagger 1}$ \\ ${ }^{1}$ Department of Radiology, Washington University, St. Louis, Missouri; and ${ }^{2}$ Department of Medicine, Washington University, \\ St. Louis, Missouri
}

\begin{abstract}
Atherosclerosis is the pathophysiologic process behind lethal cardiovascular diseases. It is a chronic inflammatory progression. Chemokines can strongly affect the initiation and progression of atherosclerosis by controlling the trafficking of inflammatory cells in vivo through interaction with their receptors. Some chemokine receptors have been reported to play an important role in plaque development and stability. However, the diagnostic potential of chemokine receptors has not yet been explored. The purpose of this study was to develop a positron emitter-radiolabeled probe to image the upregulation of chemokine receptor in a wire-injury-accelerated apolipoprotein $E$ knockout $\left(\mathrm{ApoE}^{-/}\right)$mouse model of atherosclerosis. Methods: $\mathrm{A}$ viral macrophage inflammatory protein II (VMIP-II) was used to image the upregulation of multiple chemokine receptors through conjugation with DOTA for ${ }^{64} \mathrm{Cu}$ radiolabeling and PET. Imaging studies were performed at 2 and $4 \mathrm{wk}$ after injury in both wire-injured $\mathrm{ApoE}^{-/-}$ and wild-type C57BL/6 mice. Competitive PET blocking studies with nonradiolabeled VMIP-II were performed to confirm the imaging specificity. Specific PET blocking with individual chemokine receptor antagonists was also performed to verify the upregulation of a particular chemokine receptor. In contrast, ${ }^{18} \mathrm{~F}-\mathrm{FDG}$ PET imaging was performed in both models to evaluate tracer uptake. Immunohistochemistry on the injury and sham tissues was performed to assess the upregulation of chemokine receptors. Results: ${ }^{15} \mathrm{O}-\mathrm{CO}$ PET showed decreased blood volume in the femoral artery after the injury. ${ }^{64} \mathrm{Cu}$-DOTA-vMIP-II exhibited fast in vivo pharmacokinetics with major renal clearance. PET images showed specific accumulation around the injury site, with consistent expression during the study period. Quantitative analysis of tracer uptake at the injury lesion in the $\mathrm{ApoE}^{-/-}$model showed a 3-fold increase over the sham-operated site and the sites in the injured wildtype mouse. ${ }^{18} \mathrm{~F}-\mathrm{FDG}$ PET showed significantly less tracer accumulation than ${ }^{64} \mathrm{Cu}$-DOTA-vMIP-II, with no difference observed between injury and sham sites. PET blocking studies identified chemokine receptor-mediated ${ }^{64} \mathrm{Cu}$-DOTA-vMIP-II uptake and verified the presence of 8 chemokine receptors, and this finding was confirmed by immunohistochemistry. Conclusion: ${ }^{64} \mathrm{Cu}$-DOTA-vMIP-II was proven a sensitive and useful PET imaging probe for the detection of 8 up-regulated chemokine receptors in a model of injury-accelerated atherosclerosis.
\end{abstract}

Key Words: chemokine receptors; positron emission tomography; virus macrophage inflammatory protein; atherosclerosis; molecular imaging

J Nucl Med 2013; 54:1135-1141

DOI: 10.2967/jnumed.112.114777

Received Sep. 26, 2012; revision accepted Jan. 14, 2013.

For correspondence or reprints contact: Yongjian Liu, Department of Radiology, Washington University, Campus Box 8225, 510 S. Kingshighway

Blvd., St. Louis, MO 63110.

E-mail: liuyo@mir.wustl.edu

tDeceased.

Published online May 8, 2013.

COPYRIGHT (C) 2013 by the Society of Nuclear Medicine and Molecular Imaging, Inc.
D espite the substantial decrease in cardiovascular diseases such as myocardial infarction and stroke over the last few decades, they remain the leading cause of death in the United States and are on the rise worldwide. Mortality data for 2008 show that cardiovascular diseases accounted for $32.8 \%$ of overall deaths and were associated with an estimated cost of about $\$ 300$ billion in the United States (1). Despite the recent advances in cardiovascular disease diagnosis, there is an urgent need to develop imaging approaches not only for late-stage assessment of the anatomic severity of vascular stenosis but also, more importantly, for early detection of the biologic process at a molecular level and for risk stratification (2). Atherosclerosis, which is the pathophysiologic process behind cardiovascular diseases, is characterized by the progressive accumulation of fat and cholesterol in arterial walls (3). Currently, atherosclerosis is understood as a chronic inflammatory process elicited by hyperlipidemia. It is perpetuated by a dysregulated immune response eliciting the development of lipid-rich plaques in the larger arteries of the body (4,5). Atherosclerosis involves numerous cellular and molecular components that have led to the identification of many targets expressed during the progression of the plaque for various biomedical research including diagnosis and therapy (6-9).

In the last decade, molecular imaging has played a critical role in this transition by addressing diagnostic challenges such as understanding the molecular pathways involved in atherosclerosis, monitoring plaque progression, and identifying the mechanism underlying the complications of human atherosclerotic plaques (10). Among various imaging modalities, although MR imaging has made significant progress in characterization of plaque composition, progression, and regression, radionuclide-based techniques including SPECT and especially PET have been favored because of their high sensitivity and functional imaging $(11,12)$. Till now, many PET probes have been developed for atherosclerosis diagnosis via a variety of biomarkers (10). However, most of these targets represent only particular biologic processes of the progression of atherosclerosis and provide limited information for treatment and prevention of the disease. Because of the severity and complexity of atherosclerosis, there is an urgent need to develop functional imaging probes to monitor the initiation and evolution of atherosclerosis while reflecting the biologic processes that represent the most likely or informative aspects of the therapeutic target (6).

It has been reported that inflammatory factors play critical roles at all stages of atherosclerosis, including initiation, progression, and final clinical manifestation $(13,14)$. Lately, with the new understanding of the pathophysiology of atherosclerosis, chemokines have been discovered to have strong effects on the progression of 
the disease by controlling the trafficking of inflammatory cells in the body (15). Chemokines are proteins containing 70-80 amino acids with a characteristic 3-dimensional fold that is involved in guiding and activating distinct leukocyte subsets. Because of the positioning of the first 2 closely paired and highly conserved cysteines of the amino acid sequence, located near their $\mathrm{N}$ terminus, they can be divided into 4 groups: $\mathrm{CXC}, \mathrm{CX}_{3} \mathrm{C}, \mathrm{CC}$, and $\mathrm{C}$. The specific effects of the chemokines on their target cells are mediated by members of a family of 7-transmembrane-spanning, G-proteincoupled chemokine receptors (16). Among chemokine receptors, C$\mathrm{C}$ chemokine receptor type 1 (CCR1), C-C chemokine receptor type 2 (CCR2), CX3C chemokine receptor type 1 (CX3CR1), and C-X-C chemokine receptor type 4 (CXCR4) participate in vascular inflammation through multiple cellular processes in both murine and human studies as well as playing a pivotal role in the progression of the plaque (17-19). Therefore, many chemokine-receptor antagonists are presently being explored for their therapeutic potential in atherosclerosis treatment $(20,21)$. For example, C-C chemokine receptor type 5 (CCR5) is well documented as playing an important role in the later stages of plaque development (22) and is currently being explored as a candidate target for atherosclerosis treatment with its antagonist, maraviroc (23). However, to our knowledge the diagnostic capability of chemokine receptors, especially using PET for imaging atherosclerosis, has not been assessed.

The current focus of cardiovascular medicine is on early detection and prevention of disease to control the escalating costs of health care. However, the most widely used PET tracer, ${ }^{18} \mathrm{~F}-\mathrm{FDG}$, monitors only glucose metabolism and lacks specificity for atherosclerosis (24). Because of the importance of chemokine receptors in atherosclerosis, a viral macrophage inflammatory protein II, vMIP-II, was selected for multiple chemokine receptor targeting in a wire-injuryaccelerated apolipoprotein E knockout $\left(\mathrm{ApoE}^{-/-}\right)$atherosclerosis model by conjugating the vMIP-II with DOTA for ${ }^{64} \mathrm{Cu}$ PET imaging $(9,25,26)$. This work provides a new platform for specific chemokine receptor PET imaging and a range of theranostic applications in atherosclerosis.

\section{MATERIALS AND METHODS}

Materials were purchased from Sigma-Aldrich and used without further purification unless otherwise stated. DOTA- $N$-hydroxysuccinimide ester was purchased from Macrocyclics. Chemokine receptor antagonists 4-(4-chlorophenyl)-4-hydroxy- $\alpha, \alpha$-diphenyl-1-piperidinepentanenitrile hydrochloride for CCR1, 6-methyl-1'-[2-(5-methyl-2phenyl-4-oxazolyl)ethyl]-spiro[4H-3,1-benzoxazine-4,4'-piperidin]-2 (1H)-one for CCR2, $N$-(1-naphthalenylcarbonyl)-4-nitro-L-phenylalanine methyl ester for $\mathrm{C}-\mathrm{C}$ chemokine receptor type 3 (CCR3), 2-[1,4'-bipiperidin]-1'-yl- $N$-cycloheptyl-6,7-dimethoxy-4-quinazolinamine dihydrochloride for C-C chemokine receptor type 4 (CCR4), 4-difluoro- $N$-\{(1S)-3-[3-(3-isopropyl-5-methyl-4H-1,2,4-triazol-4-yl)8-azabicyclo[3.2.1]oct-8-yl]-1-phenylpropyl\}cyclohexanecarboxamide for CCR5, 2-[2-[4-[(3-phenoxyphenyl)methyl]-1-piperazinyl]ethoxy] ethanol dihydrochloride for C-C chemokine receptor type 8 (CCR8), and 1,1'-[1,4-phenylenebis-(methylene)]-bis-(1,4,8,11-tetraazacyclotetradecane)octahydrochloride for CXCR4 were purchased from Tocris. Anti-CX3CR1 antibody and anti-CXCR4 antibody were purchased from Abcam. Chemokine receptor antagonist peptide, viral MIP-II (vMIP-II), was purchased from R\&D systems.

\section{DOTA-vMIP-II Conjugation, Radiolabeling, and Serum Stability Assay}

DOTA-VMIP-II conjugation was performed by incubating $1.0 \mathrm{mg}$ of vMIP-II with $2.0 \mathrm{mg}$ of DOTA- $N$-hydroxysuccinimide ester in
$100 \mathrm{mM}$ phosphate buffer ( $\mathrm{pH}$ 7.0) prechelexed for removal of trace metals at $4^{\circ} \mathrm{C}$ overnight, followed by purification with solid-phase extraction (C-18 Sep-Pak cartridges; Waters) and reversed-phase highperformance liquid chromatography (HPLC). Reversed-phase HPLC was performed on a Dionex system equipped with an ultraviolet and visible light detector and a radioisotope detector (B-FC-3200; BioScan Inc.) on a C-18 column ( $5 \mathrm{~mm}, 4.6 \times 220 \mathrm{~mm}$; Perkin Elmer). The linear gradient was from $100 \% \mathrm{H}_{2} \mathrm{O}$ to $65 \%$ acetonitrile in $45 \mathrm{~min}$ at a flow rate of $1 \mathrm{~mL} / \mathrm{min}$ and an ultraviolet absorbance at $210 \mathrm{~nm}$. The conjugation efficiency was more than $95 \%$ according to reversedphase HPLC. The identity of DOTA-vMIP-II was confirmed by matrix-assisted laser desorption ionization time-of-flight mass spectrometry with an average of 7.5 DOTA molecules per vMIP-II peptide (Voyager-DE STR workstation; Applied Biosystems).

${ }^{64} \mathrm{Cu}$ (half-life, $12.7 \mathrm{~h} ; \beta^{+}=17 \% ; \beta^{-}=40 \%$ ) was produced at the Washington University cyclotron facility by ${ }^{64} \mathrm{Ni}(\mathrm{p}, \mathrm{n}){ }^{64} \mathrm{Cu}$ nuclear reaction, with a specific activity of $0.74-2.96 \mathrm{GBq} / \mu \mathrm{g}$ at the end of bombardment (27). DOTA-vMIP-II $(20 \mu \mathrm{g}, \sim 2.4 \mathrm{nmol})$ was incubated with ${ }^{64} \mathrm{Cu}(220 \mathrm{MBq})$ in $100 \mu \mathrm{L}$ of $0.1 \mathrm{M} \mathrm{NH}_{4} \mathrm{OAc}$ buffer $(\mathrm{pH}$ $5.5)$ at $45^{\circ} \mathrm{C}$ for $1 \mathrm{~h}$, with a yield of $81.2 \% \pm 7.2 \%(n=15)$ according to radio-instant thin-layer chromatography (BioScan Inc.), followed by C18 Sep-Pak purification. The stability of ${ }^{64} \mathrm{Cu}$-DOTA-vMIP-II was evaluated in mouse serum (Sigma-Aldrich) at $37^{\circ} \mathrm{C}$ for $1 \mathrm{~h}$ and determined from the percentage of intact ${ }^{64} \mathrm{Cu}$-DOTA-vMIP-II in the radiochromatogram.

\section{Model of Accelerated Murine Atherosclerosis}

All animal studies were performed in compliance with guidelines set forth by the National Institutes of Health Office of Laboratory Animal Welfare and approved by the Washington University Animal Studies Committee. The accelerated-atherosclerosis model was induced in $\mathrm{ApoE}^{-1-}$ mice $(n=25$, Taconic Inc.) through wire injury as described previously $(28,29)$. Briefly, $\mathrm{ApoE}^{-1-}$ mice 6 wk old were fed a Western diet (Harlan Teklad) (42\% fat) for 2 wk before the procedure. Each mouse was anesthetized with a standard inhaled-anesthetic protocol (1.5\%-2\% isoflurane) by induction in a chamber, and maintenance anesthesia was administered via a nose cone. The ventral sides of the hind limbs were shaved and swabbed with povidoneiodine and alcohol to create an aseptic region. An incision was made in the right femoral region using a surgical microscope (up to $\times 50$ ). The femoral artery and vein were isolated using 6-0 silk sutures. Then, the femoral artery branch was established using a small incision and was made into the vessel with microscissors. A $0.008-\mathrm{mm}$ hydrophilic guide wire (Mirage, ev3; Endovascular Inc.) was inserted into the branch and advanced approximately $2 \mathrm{~cm}$ into the descending aorta and left there for $1 \mathrm{~min}$ to induce endothelial injury. The guide wire was withdrawn and the branch was tied off. The femoral incision was closed with a 3-0 silk suture using interrupted surgical knots. The left femoral artery was also surgically prepared by undergoing incision and closure but without guide wire endothelial injury and served as the sham site. Wild-type C57BL/6 mice $(n=5)$ fed with normal chow underwent the same wire-injury procedure and were used as control animals.

\section{Blood Clearance and Biodistribution Studies}

The pharmacokinetics of the tracer were determined in normal C57BL/6 mice $(n=4)$. Approximately $370 \mathrm{kBq}$ of ${ }^{64} \mathrm{Cu}$-DOTAvMIP-II were injected through the tail vein, and blood samples were collected at multiple time points. The radioactivity of the blood samples was counted in a $\gamma$-counter (Beckman 8000) and expressed as percentage injected dose (\%ID) per gram.

${ }^{64} \mathrm{Cu}$-DOTA-vMIP-II, with more than $95 \%$ radiochemical purity, was reconstituted in $0.9 \%$ sodium chloride (APP Pharmaceuticals) for intravenous injection. Male C57BL/6 mice weighing 20-25 g ( $n=4$ /group) were injected with $370 \mathrm{kBq}$ of ${ }^{64} \mathrm{Cu}$-DOTA-vMIP-II 
$\left(2-2.5 \times 10^{-3} \mathrm{mg} / \mathrm{kg}\right.$ of body weight) in $100 \mu \mathrm{L}$ of saline via the tail vein under anesthesia. The mice were reanesthetized before they were euthanized by cervical dislocation at $1 \mathrm{~h}$ after injection. Organs of interest were collected, weighed, and counted in a well $\gamma$-counter. Standards were prepared and measured along with the samples to calculate the $\% \mathrm{ID} / \mathrm{g}(30)$.

\section{PET Imaging with ${ }^{15} \mathrm{O}-\mathrm{CO},{ }^{64} \mathrm{Cu}-\mathrm{DOTA}$-vMIP-II, and ${ }^{18} \mathrm{~F}-\mathrm{FDG}$}

To measure the blood volume changes caused by the wire injury, about $185 \mathrm{MBq}$ of ${ }^{15} \mathrm{O}-\mathrm{CO}$ (half-life, $2.07 \mathrm{~min} ; \beta^{+}=99.9 \%$ ) were mixed with nitrogen $\left({ }^{15} \mathrm{O}-\mathrm{CO} / \mathrm{N}_{2}<0.3 \% \mathrm{v} / \mathrm{v}\right)$ and delivered to the mice through an anesthesia line close to the nose cone via a 3-way stopcock at 2 wk after the wire injury (31). A 0 - to 5-min dynamic scan was immediately obtained after the inhalation of ${ }^{15} \mathrm{O}-\mathrm{CO}$ on an Inveon PET/CT system (Siemens). The relative blood volume change was evaluated by standardized uptake values in 3-dimensional regions of interest by averaging the activity concentration corrected for decay over the contained voxels (multiple image slices) (32).

Two and $4 \mathrm{wk}$ after the wire injury, small-animal PET imaging was performed on $\mathrm{ApoE}^{-1-}$ mice $(n=15)$ to determine ${ }^{64} \mathrm{Cu}$-DOTAvMIP-II uptake and progression at atheroscleroticlike lesions. The injured control C57BL/6 mice $(n=5)$ were scanned following the same protocol. For PET imaging, the mice were injected with ${ }^{64} \mathrm{Cu}-$ DOTA-vMIP-II (1.85-3.7 MBq in $100 \mu \mathrm{L}$ of saline), and 0- to 60-min dynamic scans were acquired on the microPET Focus-220 or Inveon PET/CT system (Siemens). Both PET scanners were cross-calibrated periodically. The PET image data were analyzed using the manufacturer's software (ASI Pro or IRW). The accumulation of ${ }^{64} \mathrm{Cu}$-DOTAvMIP-II at the injury site and on the contralateral sham-operated femoral artery was calculated as standardized uptake values. Additionally, ${ }^{18} \mathrm{~F}$-FDG PET was performed on both $\operatorname{ApoE}^{-1-}(n=15)$ and C57BL/6 mice $(n=5)$ following the same imaging protocol with the administration of $11.1-14.8 \mathrm{MBq}$ of ${ }^{18} \mathrm{~F}-\mathrm{FDG} 1 \mathrm{~d}$ before ${ }^{64} \mathrm{Cu}$-DOTAvMIP-II was injected. Eight to $12 \mathrm{~h}$ before each ${ }^{18} \mathrm{~F}-\mathrm{FDG}$ imaging session, the mice were kept fasting but were allowed drinking water ad libitum. After the last PET scan, the animals were euthanized by cervical dislocation, and the femoral vessels were perfusion-fixed in situ with freshly prepared $4 \%$ paraformaldehyde solution for histopathology and immunohistochemistry.

\section{Competitive Receptor Blocking PET Studies}

Competitive receptor blocking studies were performed on the $\mathrm{ApoE}^{-1-}$ mice with wire injuries for ${ }^{64} \mathrm{Cu}$-DOTA-vMIP-II $(24.7-$ $49.4 \mathrm{pmol})$ by coinjection of unlabeled vMIP-II peptide (24.7-49.4 nmol) (a 1,000:1 molar ratio of vMIP-II: ${ }^{64} \mathrm{Cu}$-DOTA-vMIP-II, $n=6$ ) at $3 \mathrm{wk}$ after the wire injury followed by 0 - to 60-min dynamic PET scans. For the 8 individual chemokine receptor blocking studies, a molar ratio of 200:1 (individual chemokine receptor inhibitor: ${ }^{64} \mathrm{Cu}$ DOTA-vMIP-II) was used. For CX3CR1, since no small-molecule antagonist is commercially available, an antibody was used as a blockade, which was preinjected $4 \mathrm{~h}$ before the administration of ${ }^{64} \mathrm{Cu}-$ DOTA-vMIP-II.

\section{Immunohistochemistry}

Femoral arteries collected from imaging studies were embedded in paraffin for sectioning at $5 \mu \mathrm{m}$. After removal of the wax and rehydration, the sections were treated with serum to block nonspecific binding. The sections were then incubated at room temperature for $1 \mathrm{~h}$, once with primary antibodies specific to unique chemokines expressed by cells that accumulate in arterial plaques and then once with secondary antibodies conjugated to alkaline phosphatase. After incubation with a color substrate that was activated by alkaline phosphatase to give an intense blue color, the sections were counterstained with nuclear fast red to reveal the tissue architecture. Digital images of the stained sections were obtained using a scanning light microscope (NanoZoomer; Hamamatsu) for image analysis to determine the percentage of cells positive for the CCR1, CCR2, CCR3, CCR4, CCR5, CCR8, CX3CR1, and CXCR4 chemokine receptors.

\section{Statistical Analysis}

Group variation is described as mean $\pm \mathrm{SD}$. Groups were compared using a 1-way ANOVA with a Bonferroni post hoc test. Differences within individual groups were determined with a 2-tailed Mann-Whitney test. The significance level in all tests was set at a $P$ value of less than 0.05. Prism, version 5.02 (GraphPad), was used for all statistical analyses.

\section{RESULTS}

\section{${ }^{64} \mathrm{Cu}$ Radiolabeling and Serum Stability}

The radiochemical purity of the ${ }^{64} \mathrm{Cu}$-DOTA-vMIP-II was always more than $98 \%$, confirmed with radio-HPLC, and the radiolabeling specific activity was $74.9 \pm 8.3 \mathrm{MBq} / \mathrm{nmol}(n=25)$. After $1 \mathrm{~h}$ of incubation at $37^{\circ} \mathrm{C}$ in mouse serum, the radiochemical integrity of ${ }^{64} \mathrm{Cu}$-DOTA-vMIP-II was still more than $95 \%$, indicating the stability of this tracer during the 1-h imaging session.

\section{Blood Clearance and Biodistribution of ${ }^{64} \mathrm{Cu}$-DOTA-vMIP-II}

The blood curve in normal C57BL/6 mice showed that the ${ }^{64} \mathrm{Cu}$-DOTA-vMIP-II tracer cleared rapidly from the blood. At 1 min after injection, the blood retention sharply decreased to about $50 \% \mathrm{ID} / \mathrm{g}$. It further decreased to $12.0 \pm 1.0 \% \mathrm{ID} / \mathrm{g}$ at $10 \mathrm{~min}$ after injection and then gradually declined to $2.3 \pm 0.3$ $\% \mathrm{ID} / \mathrm{g}$ at $60 \mathrm{~min}$ after injection $(n=4$, Supplemental Fig. 1A). In addition, the clearance of ${ }^{64} \mathrm{Cu}$-DOTA-vMIP-II from $\mathrm{ApoE}^{-1-}$ mouse PET images showed a similar profile.

Biodistribution data showed a fast clearance profile of ${ }^{64} \mathrm{Cu}$ DOTA-vMIP-II primarily through the kidneys, with minor accumulation in the liver and lungs and negligible uptake in other organs (Fig. 1), consistent with other reported peptide tracers (9). At $1 \mathrm{~h}$ after injection, the blood accumulation of ${ }^{64} \mathrm{Cu}-$ DOTA-vMIP-II was only $1.48 \pm 0.34 \% \mathrm{ID} / \mathrm{g}$, whereas liver accumulation was $8.67 \pm 2.04 \% \mathrm{ID} / \mathrm{g}$. However, kidney retention was $183.2 \pm 44.2 \% \mathrm{ID} / \mathrm{g}, 20$ times higher than liver uptake.

\section{PET Imaging with ${ }^{15} \mathrm{O}-\mathrm{CO},{ }^{64} \mathrm{Cu}$-DOTA-vMIP-II, and ${ }^{18} \mathrm{~F}-\mathrm{FDG}$}

${ }^{15} \mathrm{O}-\mathrm{CO}$ is an intravascular tracer transported by red blood cells and has been commonly used to measure blood volume (33). Two

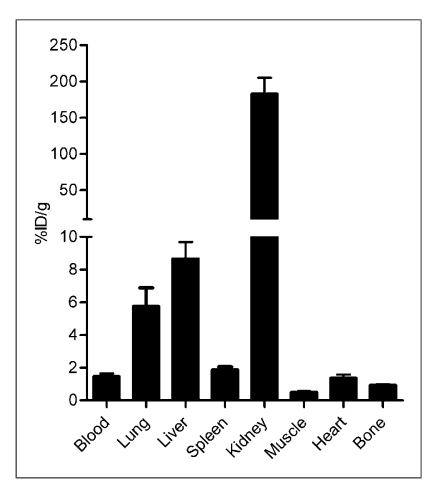
${ }^{64} \mathrm{Cu}$-DOTA-vMIP-II in C57BL/6 mice showing fast renal clearance at $1 \mathrm{~h}$ after injection $(n=$ 4/group).
FIGURE 1. Biodistribution of weeks after injury, the blood volume at the injured artery sharply decreased (Supplemental Fig. 2A). Quantitative dynamic analysis showed that the standardized uptake values of the injury and sham arteries reached stability at the end of the PET scan and averaged $0.11 \pm 0.01 \% \mathrm{ID} / \mathrm{g}$ and $0.06 \pm 0.01 \% \mathrm{ID} / \mathrm{g}$, respectively (Supplemental Fig. 2B). The decrease in standardized uptake values indicates narrowing of the artery, reasonably owing to the development of atherosclerotic plaque, as was consistent with a previous report (34). 


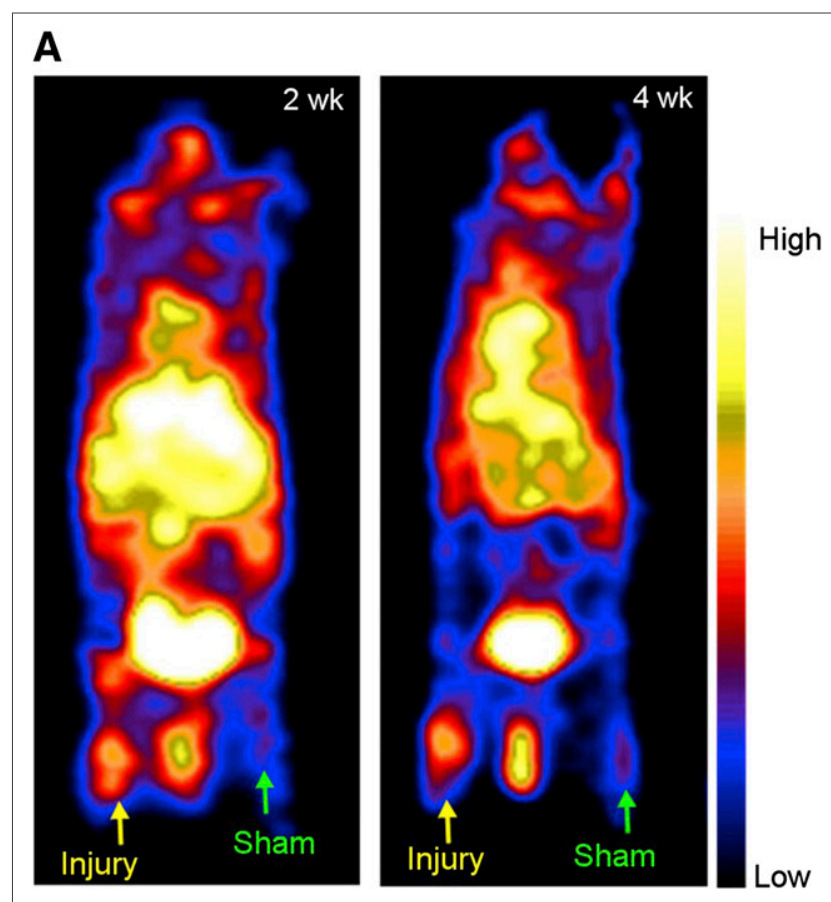

B

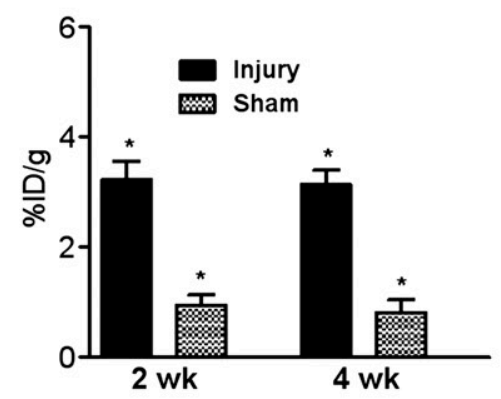

C

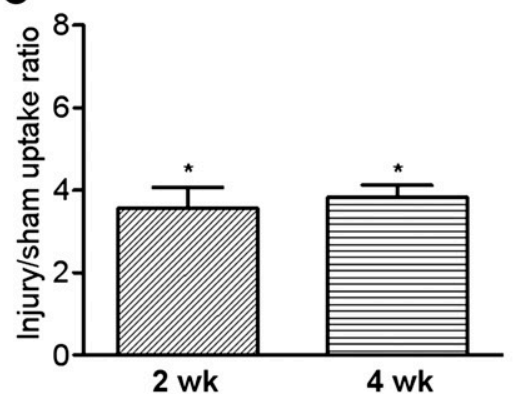

FIGURE 2. (A) ${ }^{64} \mathrm{Cu}$-DOTA-vMIP-II PET images (0- to 60-min dynamic scans) of wire-injured $\mathrm{ApoE}^{-/-}$mice at 2 and 4 wk after injury showing accumulation of activity at injury lesion but little uptake in contralateral sham-operated thigh. (B and C) Graphs showing ${ }^{64} \mathrm{Cu}$-DOTA-vMIP-II accumulation at injury and sham sites (B) and ${ }^{64} \mathrm{Cu}-\mathrm{DOTA}$-vMIP-II injury-to-sham uptake ratios $(\mathrm{C})$ at studied time points. ${ }^{*} P<0.001$.

PET images clearly showed ${ }^{64} \mathrm{Cu}$-DOTA-vMIP-II tracer uptake at the site of induced atherosclerosis at both 2 and 4 wk after the injury, whereas the sham site had only weak accumulation of activity (Fig. 2A). ${ }^{64} \mathrm{Cu}$-DOTA-vMIP-II uptake at the injury site was $3.22 \pm 0.75 \% \mathrm{ID} / \mathrm{g}(n=15)$ and $2.98 \pm 0.69 \% \mathrm{ID} / \mathrm{g}(n=10)$ at 2 and 4 wk after injury, respectively, significantly $(P<0.0001)$ higher than the corresponding data obtained from sham sites at both time points $(0.94 \pm 0.19 \% \mathrm{ID} / \mathrm{g}$ and $0.80 \pm 0.24 \% \mathrm{ID} / \mathrm{g}$, respectively) (Fig. 2B). In the $\mathrm{C} 57$ wire-injury mice, 2 wk after injury, localization of ${ }^{64} \mathrm{Cu}$-DOTA-vMIP-II at the injury lesion was observed, with no statistical difference between the injury and sham sites (Figs. 3A and 3C). The injury uptakes were $0.77 \pm$ $0.10(n=5)$ and $0.87 \pm 0.15(n=5)$ at 2 and $4 \mathrm{wk}$, respectively, significantly $(P<0.005$ for both) lower than that obtained at the injury lesion in the ApoE ${ }^{-/-}$models (Fig. 3C). For the ${ }^{18} \mathrm{~F}-\mathrm{FDG}$ studies in $\mathrm{ApoE}^{-1-}$ mice, tracer accumulation at the injury site was similar to that at the sham site, with no significant difference between the 2 time points (Figs. 3B and 3D). Importantly, uptake at the injury sites was significantly $(P<0.05)$ lower for ${ }^{18} \mathrm{~F}-\mathrm{FDG}$

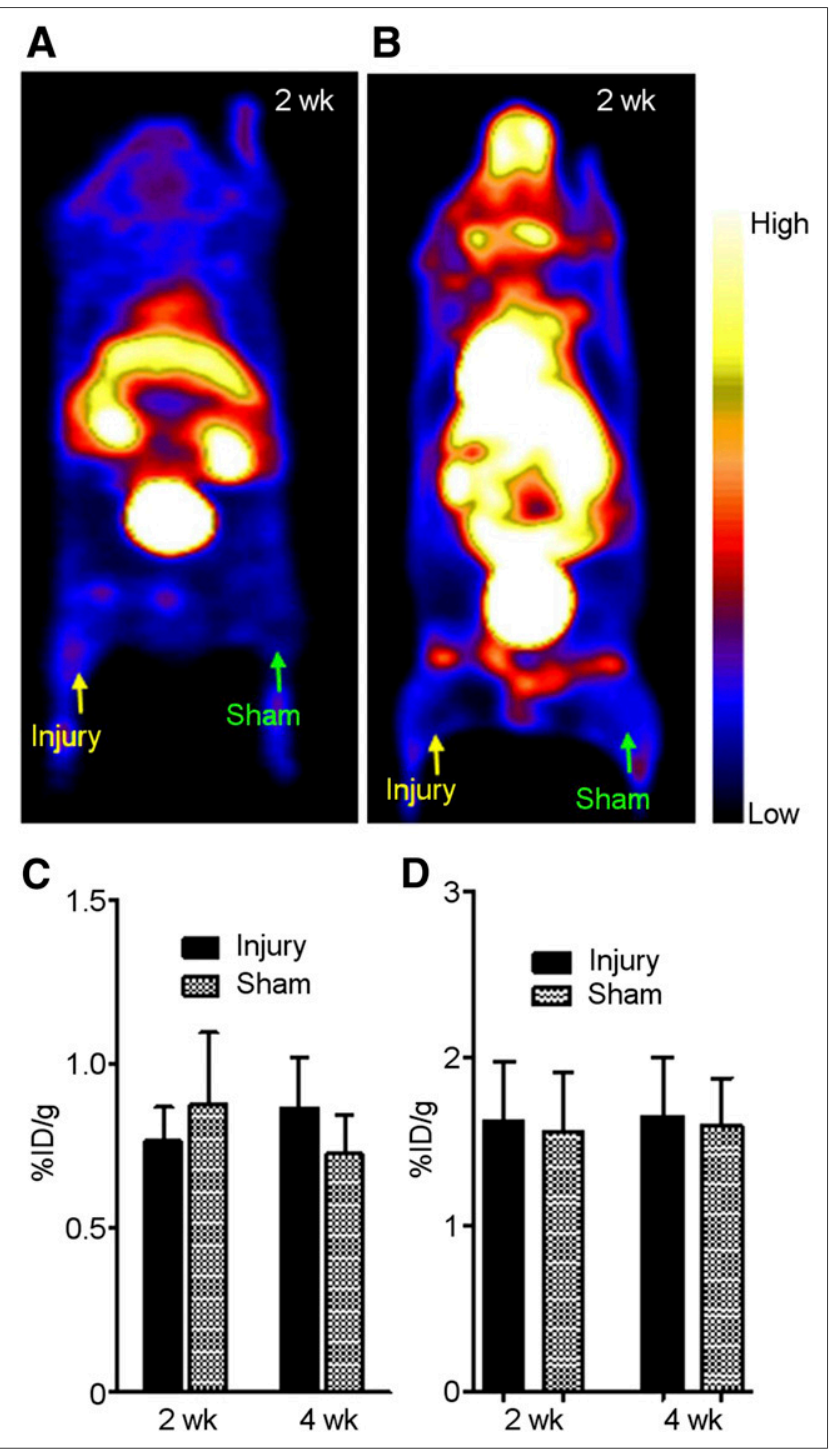

FIGURE 3. (A) Representative ${ }^{64} \mathrm{Cu}-\mathrm{DOTA}$-vMIP-II PET image (0- to 60-min dynamic scan) of wire-injured C57BL/6 wild-type mouse at 2 wk after injury showing little accumulation of activity at either injury or sham site. (B) Representative ${ }^{18} \mathrm{~F}-\mathrm{FDG}$ PET image (0- to 60-min dynamic scan) of wire-injured $\mathrm{ApoE}^{-/-}$mouse at $2 \mathrm{wk}$ after injury showing little accumulation of activity at either injury or sham site. (C) Graph showing ${ }^{64} \mathrm{Cu}$-DOTA-vMIP-II uptake analysis at both injury and sham sites at 2 and 4 wk after injury. (D) Graph showing ${ }^{18}$ F-FDG uptake analysis at both injury and sham sites at 2 and 4 wk after injury. 


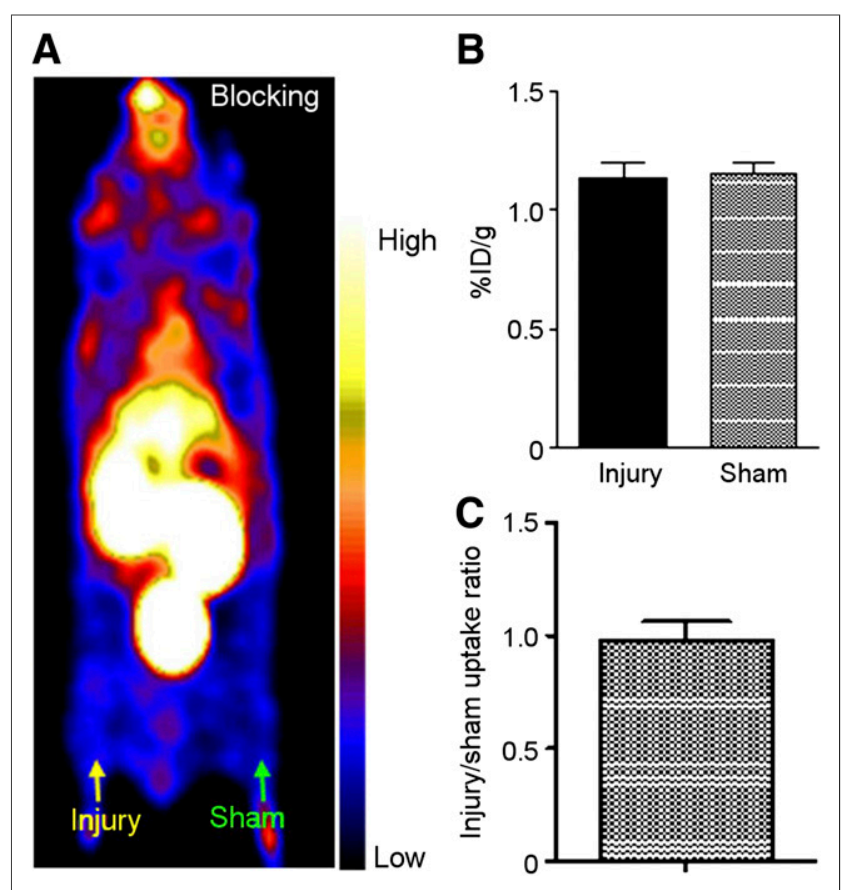

FIGURE 4. ${ }^{64} \mathrm{Cu}$-DOTA-vMIP-II blocking PET imaging study with vMIP-II (1,000-fold). (A) Representative PET image (0- to 60-min dynamic scan) showing significantly decreased activity accumulation at injury lesion, at level similar to that of sham-operated site. (B) Quantitative uptake analysis showing similar tracer localization at injury and sham sites with blockade. (C) Injury-to-sham uptake ratios with blockade.

than for ${ }^{64} \mathrm{Cu}$-DOTA-vMIP-II during the study. In the C57BL/6 model, there was no significant accumulation of ${ }^{18} \mathrm{~F}-\mathrm{FDG}$ at the injury lesion and uptake was similar to that in $\mathrm{ApoE}^{-1-}$ mice (Supplemental Figs. 3A and 3B)

\section{Competitive Chemokine Receptor Blocking}

Competitive receptor blocking with vMIP-II was performed 3 wk after injury on the mice that had been scanned 2 wk after injury without blocking. Compared with tracer accumulation at the injury lesion 2 wk after injury, the uptake value was significantly $(P<0.001, n=5)$ blocked to a level similar to that obtained at the sham site (Figs. 4A and 4B). Additionally, the injury-to-sham uptake ratio was significantly $(P<0.005)$ decreased from $3.59 \pm 0.54(n=10)$ at $2 \mathrm{wk}$ to $0.98 \pm 0.08(n=5)$ at $3 \mathrm{wk}$ (Figs. 2C and 4C).

Specific chemokine receptor blocking studies showed that ${ }^{64} \mathrm{Cu}$-DOTA-vMIP-II PET signals could be blocked with up to 8 chemokine receptor antagonists/antibodies (CCR1, CCR2, CCR3, CCR4, CCR5, CCR8, CXCR4, and CX3CR1), indicating the presence of these receptors on the injury lesion. Among them, CCR5 and CXCR4 antagonists were able to block the ${ }^{64} \mathrm{Cu}$-DOTAvMIP-II PET signal the most, with more than $20 \%$ blocking observed (Fig. 5).

\section{Immunohistochemistry}

All injured artery samples demonstrated arterial wall hypertrophy with partial luminal occlusion (Fig. 6). Signals for CCR1 and CCR4 were observed on isolated cells and the luminal surface in injured vessels. CCR2-positive cells localized to the medial layer. CCR3 and CCR8 expression was found throughout the walls of

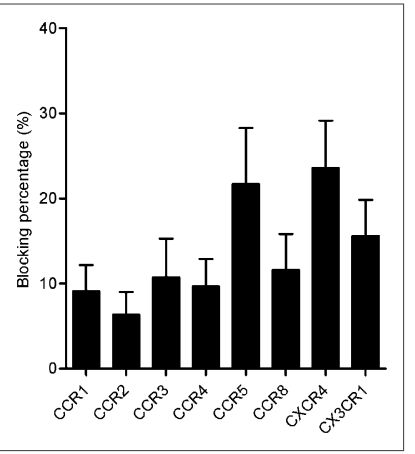

FIGURE 5. Blocking percentage for individual chemokine receptors. Individual chemokine receptor antagonists were coinjected with ${ }^{64} \mathrm{Cu}-\mathrm{DOTA}-\mathrm{vMIP-II}$ in $\mathrm{ApoE}^{-/-}$mice for PET imaging at 3 wk after injury. Decrease of ${ }^{64}$ Cu-DOTA-vMIP-II uptake, compared with uptake observed at 2 wk after injury with ${ }^{64} \mathrm{Cu}$-DOTAVMIP-II, was calculated as blocking percentage. Blocking percentages for 8 chemokine receptor antagonists ranged from $6.34 \% \pm$ $2.66 \%$ to $23.6 \% \pm 5.57 \%$.

\section{was demonstrated.}

Although many molecular agents have been developed and shown great promise in imaging various biologic processes of atherosclerosis, the chronic progression and complicated pathogenesis of the disease still make in vivo detection of plaque formation a challenge $(6,7)$. Recently, there has been growing interest in using dual- or multiple-targeting ligands to image various biomarkers expressed during different stages of atherosclerosis that showed improved diagnosis (35-38). Chemokine receptors, mostly explored for oncologic PET applications, may be good candidates for this multiple targeting strategy because of their active involvement (CCR1, CCR2, CCR3, CCR4, CCR5, CCR8, CXCR4, and CX3CR1) in the development of plaque, especially if they may even have stage-specific effects $(15,20,21,39)$. Further, on the basis of the unsuccessful clinical trial of individual chemokine receptor antagonists for cardiovascular disease treatment, it has been proposed that CCR 2 and CCR 5 be used as dual-targeting strategies for atherosclerosis because of their function in the trafficking of monocytes/macrophages and their function in other cell types relevant to disease pathogenesis. Therefore, to develop a multiple-targeting probe, it is critical to identify the presence of various chemokine receptors during the evolution of atherosclerosis. Among the compounds binding multiple chemokine receptors, vMIP-II is one that can bind several chemokine receptor families, including $\mathrm{CC}, \mathrm{CXC}$, and $\mathrm{CX} 3 \mathrm{C}$, with high affinity $(25,26)$. In this study, a vascular injury ApoE ${ }^{-1-}$ mouse model was selected. Although there has been controversy about using vascular injury $\mathrm{ApoE}^{-1-}$ mouse models for atherosclerosis research, the endothelial denudation process does cause vascular inflammation and represents a critical initiating event in the pathogenesis of atherosclerosis, which can provide rapid insight into the mechanism of chemokine receptor effects in the vasculature $(15,34,39)$.

Biodistribution studies of the vMIP-II peptide were performed through the conjugation of DOTA chelator and ${ }^{64} \mathrm{Cu}$ radiolabeling. 


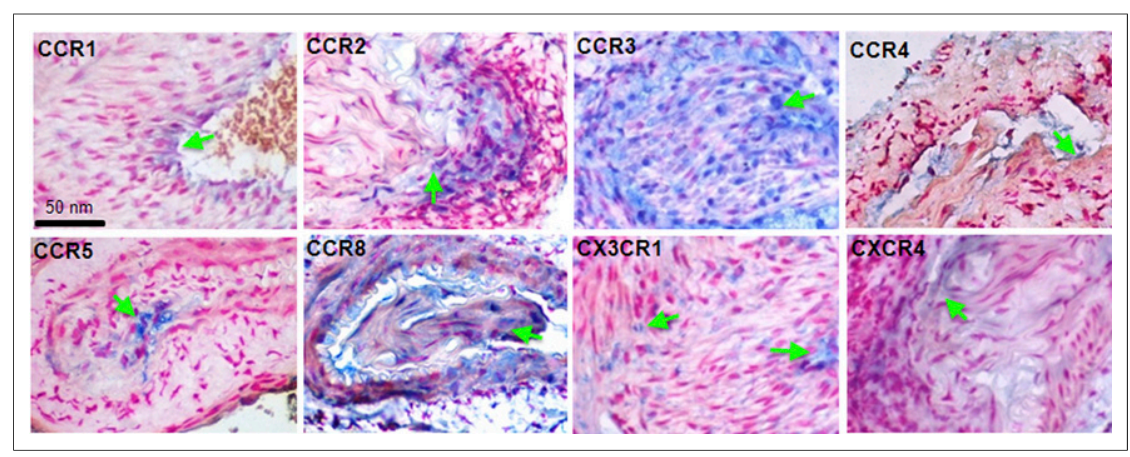

FIGURE 6. Immunohistochemistry of chemokine receptors: CCR1 signal localized to luminal surface in injured vessels, CCR2-positive cells in medial layer of injured vessels, CCR3 expression throughout walls of injured femoral arteries, CCR4 localized to isolated cells at luminal surface of injured vessels, CCR5 signal in cells medial to internal elastic lamina of injured vessels, CCR8-positive cells throughout walls of injured vessels, CX3CR1positive cells scattered through walls of injured arteries, and CXCR4 signal in scattered vessel-wall cells with injury.

Because of the high radiolabeling specific activity, only trace amounts $(2.5 \mathrm{pmol})$ of ${ }^{64} \mathrm{Cu}$-DOTA-vMIP-II were administered in vivo. In wild-type $\mathrm{C} 57 \mathrm{BL} / 6$ mice, ${ }^{64} \mathrm{Cu}$-DOTA-vMIP-II displayed rapid pharmacokinetics through renal clearance in $1 \mathrm{~h}$. As shown in Figure 2, the accumulation of ${ }^{64} \mathrm{Cu}$-DOTA-vMIP-II at the injury lesion in the $\mathrm{ApoE}^{-/-}$model was clearly visualized, with minimal accumulation observed on the contralateral sham site. Further, the imaging patterns between 2 and 4 wk after injury were similar, indicating the consistent expression of chemokine receptors during this period. The quantitative analysis showed that the injury site had almost 3-fold more uptake than the shamoperated site in $\mathrm{ApoE}^{-1-}$ mice, indicating injury-induced tracer accumulation. Interestingly, there was little tracer localization in the wire-injured C57BL/6 mice, with no difference observed between the 2 regions of interest at the same time points (Figs. 3A and 3B). Uptake at the injury lesion was significantly less (3.2-fold) than that in the $\mathrm{ApoE}^{-1-}$ mice, suggesting that the wire injury in normal C57BL/6 mice did not cause significant tracer accumulation. Further, the competitive blocking PET studies with vMIP-II peptide significantly reduced tracer uptake at the injury lesion to a level similar to that obtained at the sham site, as was confirmed by the injury-to-sham uptake ratio. All these data suggest that the ${ }^{64} \mathrm{Cu}$ DOTA-vMIP-II accumulation at the injury lesion in $\mathrm{ApoE}^{-1-}$ models was mediated mainly by the upregulation of chemokine receptors.

${ }^{18} \mathrm{~F}$-FDG PET has been widely used for atherosclerosis metabolism imaging in clinical research (24). Although reports showed a correlation between higher baseline ${ }^{18} \mathrm{~F}$-FDG uptake and subsequent cardiovascular mortality in cancer patients (40), application of ${ }^{18} \mathrm{~F}$-FDG PET in imaging plaque progression and stability is still controversial and limited. Herein, accumulation at the injury lesion was significantly less than that obtained with ${ }^{64} \mathrm{Cu}$-DOTA-vMIP-II in ApoE ${ }^{-/-}$models. Although the fact that there was no difference in ${ }^{18} \mathrm{~F}-\mathrm{FDG}$ uptake between the injury and sham sites in either the $\mathrm{ApoE}^{-1-}$ or the C57BL/6 model indicates nonspecific accumulation, tracer accumulation was slightly higher in the ApoE ${ }^{-1-}$ model than in the C57BL/6, confirming increased metabolism in this model of accelerated atherosclerosis (24).

The PET imaging results reported here confirmed that ${ }^{64} \mathrm{Cu}-$ DOTA-vMIP-II accumulation at injury lesions in the $\mathrm{ApoE}^{-1-}$ model was mediated by chemokine receptors. Thus, a specific blocking PET study was performed to verify the presence of individual chemokine receptors. As shown in Figure 5, with the blocking of individual chemokine receptor antagonists/antibodies at $3 \mathrm{wk}$ after injury, ${ }^{64} \mathrm{Cu}$-DOTA-vMIP-II uptake at the injury lesion could be reduced by 8 individual chemokine receptor antagonists/antibodies, including CCR1, CCR2, CCR3, CCR4, CCR5, CCR8, CXCR4, and CX3CR1, indicating the presence of these receptors at the injury lesions in $\mathrm{ApoE}^{-1-}$ models. Further, immunohistochemistry confirmed the upregulation of particular chemokine receptors in the injured artery samples, whereas minimal expression was observed in the artery tissue collected from the sham-operated thigh.

\section{CONCLUSION}

In this study, we used a highly sensitive ${ }^{64} \mathrm{Cu}$-DOTA-vMIP-II probe and PET imaging to demonstrate upregulation of chemokine receptors at the injury lesion of an $\mathrm{ApoE}^{-/-}$model of wire-injuryaccelerated atherosclerosis. The targeting specificity was confirmed by competitive PET blocking studies. The presence of 8 chemokine receptors was verified by individual chemokine receptor antagonist/antibody blocking studies and immunohistochemistry. In combination with nanoplatforms, vMIP-II peptide has the potential to be used as a targeting and diagnostic agent for atherosclerotic plaque.

\section{DISCLOSURE}

The costs of publication of this article were defrayed in part by the payment of page charges. Therefore, and solely to indicate this fact, this article is hereby marked "advertisement" in accordance with 18 USC section 1734. This material was based upon work supported by the National Heart, Lung and Blood Institute of the National Institutes of Health as a Program of Excellence in Nanotechnology (HHSN268201000046C). The production of ${ }^{64} \mathrm{Cu}$ was supported by the National Cancer Institute (CA86307). No other potential conflict of interest relevant to this article was reported.

\section{ACKNOWLEDGMENTS}

We dedicate this paper to the memory of Professor Michael J. Welch, a leading PET imaging scientist in the world who greatly supported this research until he passed away on May 6, 2012. We thank Nicole Fettig, Margaret Morris, Amanda Roth, Lori Strong, Ann Stroncek, and Lisa Moore for their assistance with the animal and imaging studies, and Tom Voller, Paul Eisenbies, Evelyn Madrid, Efrem Mebrahtu, and Suzanne Lapi for ${ }^{64} \mathrm{Cu}$ production. We specially thank Arun Thukkani for the helpful discussion.

\section{REFERENCES}

1. Roger VL, Go AS, Lloyd-Jones DM, et al. Heart disease and stroke statistics: 2012 update-a report from the American Heart Association. Circulation. 2012;125:e2-e220.

2. Majmudar MD, Nahrendorf M. Cardiovascular molecular imaging: the road ahead. J Nucl Med. 2012;53:673-676. 
3. Hansson GK, Libby P. The immune response in atherosclerosis: a double-edged sword. Nat Rev Immunol. 2006;6:508-519.

4. Libby P, Ridker PM, Hansson GK. Progress and challenges in translating the biology of atherosclerosis. Nature. 2011;473:317-325.

5. Libby P, Ridker PM, Hansson GK. Inflammation in atherosclerosis: from pathophysiology to practice. J Am Coll Cardiol. 2009;54:2129-2138.

6. Quillard T, Libby P. Molecular imaging of atherosclerosis for improving diagnostic and therapeutic development. Circ Res. 2012;111:231-244.

7. Sadeghi MM, Glover DK, Lanza GM, Fayad ZA, Johnson LL. Imaging atherosclerosis and vulnerable plaque. J Nucl Med. 2010;51(suppl 1):51S-65S.

8. Liu Y, Welch MJ. Nanoparticles labeled with positron emitting nuclides: advantages, methods, and applications. Bioconjug Chem. 2012;23:671-682.

9. Liu Y, Abendschein D, Woodard GE, et al. Molecular imaging of atherosclerotic plaque with ${ }^{64} \mathrm{Cu}$-labeled natriuretic peptide and PET. J Nucl Med. 2010;51:85-91.

10. Libby P, DiCarli M, Weissleder R. The vascular biology of atherosclerosis and imaging targets. J Nucl Med. 2010;51(suppl 1):33S-37S.

11. Joshi F, Rosenbaum D, Bordes S, Rudd JH. Vascular imaging with positron emission tomography. J Intern Med. 2011;270:99-109.

12. Dobrucki LW, Sinusas AJ. PET and SPECT in cardiovascular molecular imaging. Nat Rev Cardiol. 2010;7:38-47.

13. Ross R. Atherosclerosis: an inflammatory disease. N Engl J Med. 1999;340:115-126.

14. Libby P. Inflammation in atherosclerosis. Nature. 2002;420:868-874.

15. Jerath MR, Kwan M, Liu P, Patel DD. Chemokine receptors in atherosclerosis. In: Harrison JK, Lukacs NW, eds. The Chemokine Receptors. Totowa, NJ: Humana Press; 2007:199-233.

16. Murdoch C, Finn A. Chemokine receptors and their role in inflammation and infectious diseases. Blood. 2000;95:3032-3043.

17. Gerszten RE, Tager AM. The monocyte in atherosclerosis: should I stay or should I go now? N Engl J Med. 2012;366:1734-1736.

18. McPherson R, Davies RW. Inflammation and coronary artery disease: insights from genetic studies. Can J Cardiol. 2012;28:662-666.

19. Schieffer B, Luchtefeld M. Emerging role of chemokine receptor 7 in atherosclerosis. Trends Cardiovasc Med. 2011;21:211-216.

20. Koenen RR, Weber C. Chemokines: established and novel targets in atherosclerosis. EMBO Mol Med. 2011;3:713-725.

21. Koenen RR, Weber C. Therapeutic targeting of chemokine interactions in atherosclerosis. Nat Rev Drug Discov. 2010;9:141-153.

22. Potteaux S, Combadiere C, Esposito B, et al. Role of bone marrow-derived CC-chemokine receptor 5 in the development of atherosclerosis of low-density lipoprotein receptor knockout mice. Arterioscler Thromb Vasc Biol. 2006;26: 1858-1863.

23. Jones KL, Maguire JJ, Davenport AP. Chemokine receptor CCR5: from AIDS to atherosclerosis. Br J Pharmacol. 2011;162:1453-1469.

24. Buettner C, Rudd JH, Fayad ZA. Determinants of FDG uptake in atherosclerosis. JACC Cardiovasc Imaging. 2011;4:1302-1304.
25. Lüttichau HR, Johnsen AH, Jurlander J, Rosenkilde MM, Schwartz TW. Kaposi sarcoma-associated herpes virus targets the lymphotactin receptor with both a broad spectrum antagonist vCCL2 and a highly selective and potent agonist vCCL3. J Biol Chem. 2007;282:17794-17805.

26. Kledal TN, Rosenkilde MM, Coulin F, et al. A broad-spectrum chemokine antagonist encoded by Kaposi's sarcoma-associated herpesvirus. Science. 1997;277:1656-1659.

27. McCarthy DW, Shefer RE, Klinkowstein RE, et al. Efficient production of high specific activity ${ }^{64} \mathrm{Cu}$ using a biomedical cyclotron. Nucl Med Biol. 1997;24:3543.

28. Westrick RJ, Winn ME, Eitzman DT. Murine models of vascular thrombosis (Eitzman series). Arterioscler Thromb Vasc Biol. 2007;27:2079-2093.

29. Zhang J, Nie L, Razavian M, et al. Molecular imaging of activated matrix metalloproteinases in vascular remodeling. Circulation. 2008;118:1953-1960.

30. Liu Y, Ibricevic A, Cohen JA, et al. Impact of hydrogel nanoparticle size and functionalization on in vivo behavior for lung imaging and therapeutics. Mol Pharm. 2009;6:1891-1902.

31. Mathias CJ, Welch MJ, Green MA, et al. In vivo comparison of copper bloodpool agents: potential radiopharmaceuticals for use with copper-62. J Nucl Med. 1991;32:475-480.

32. Liu Y, Pressly ED, Abendschein DR, et al. Targeting angiogenesis using a C-type atrial natriuretic factor-conjugated nanoprobe and PET. J Nucl Med. 2011;52: 1956-1963.

33. Lehtiö K, Oikonen V, Gronroos T, et al. Imaging of blood flow and hypoxia in head and neck cancer: initial evaluation with $\left[{ }^{15} \mathrm{O}\right] \mathrm{H}_{2} \mathrm{O}$ and $\left[{ }^{18} \mathrm{~F}\right]$ fluoroerythronitroimidazole PET. J Nucl Med. 2001;42:1643-1652.

34. Ip JH, Fuster V, Badimon L, Badimon J, Taubman MB, Chesebro JH. Syndromes of accelerated atherosclerosis: role of vascular injury and smooth muscle cell proliferation. J Am Coll Cardiol. 1990;15:1667-1687.

35. Zhao Q. Dual targeting of CCR2 and CCR5: therapeutic potential for immunologic and cardiovascular diseases. J Leukoc Biol. 2010;88:41-55.

36. Ferrante EA, Pickard JE, Rychak J, Klibanov A, Ley K. Dual targeting improves microbubble contrast agent adhesion to VCAM-1 and P-selectin under flow. J Control Release. 2009;140:100-107.

37. Haider N, Hartung D, Fujimoto S, et al. Dual molecular imaging for targeting metalloproteinase activity and apoptosis in atherosclerosis: molecular imaging facilitates understanding of pathogenesis. J Nucl Cardiol. 2009;16:753762.

38. McAteer MA, Schneider JE, Ali ZA, et al. Magnetic resonance imaging of endothelial adhesion molecules in mouse atherosclerosis using dual-targeted microparticles of iron oxide. Arterioscler Thromb Vasc Biol. 2008;28:77-83.

39. Zernecke A, Weber C. Chemokines in the vascular inflammatory response of atherosclerosis. Cardiovasc Res. 2010;86:192-201.

40. Sheikine Y, Akram K. FDG-PET imaging of atherosclerosis: do we know what we see? Atherosclerosis. 2010;211:371-380. 